\title{
A Study on Chinese Students' WTC Inside the Classroom Under the Influences of Situational Variable
}

\author{
Jiaxin Zuo \\ Department of Foreign Languages and Culture \\ North Sichuan Medical College \\ Nanchong, China
}

\begin{abstract}
This study adopts quantitative and qualitative analysis to figure out the relationship between students' willingness to communicate in English inside the classroom environment and situational variable. Interlocutors, topic and conversational context are three key aspects. Thus, we find out that situational variable does influence students' willingness to communicate in English inside the classroom. Interlocutors are mainly among classmates and teacher, while topic and conversational context mainly confines to limited teaching materials in English class. Therefore, teacher should attach more significance to situational variable for increasing students' sense of security and interest, and cultivating students' willingness to communicate.
\end{abstract}

Keywords-willingness to communicate; situational variable; interlocutor; topic; conversational context

\section{INTRODUCTION}

"Willingness to communicate" (WTC), as a new variable affecting interlocutors' intention to communicate and real communication behaviors (McCroskey and Richmond, 1987), originated from the field of speech communication. Since real communication and second language pedagogy are closely tied together, researchers in Second Language Acquisition attach more importance to WTC. In 1998, MacIntyre, P. D., Clément, R., Dornyei, Z. \& Noels, K. A. argued that creating WTC for language learner is a significant goal in L2 instruction and redefined WTC as "a readiness to enter into discourse at a particular time with a particular person or persons, using an L2" (1998: 547). During the language learning process, there are some specific differences between second language learning and foreign language learning, leading to different approaches or strategies among second and foreign language teaching. Muriel Saville-Troike (2006) distinguished the differences between second and foreign language. Second language was a dominant language mostly serving for the social or official purposes, usually obtained by members of minority group who spoke another native language. Also, second language was often used for its basic function in the field of education, employment or public service. Foreign language, however, was not widely used as a dominant language by learners. It was not acquired for daily communication or used in the learners' immediate social context, but studied for crosscultural communication situations with little language exposure or with no direct practical application. Therefore, we should consider western context, eastern context, second language learning and foreign language learning independently in the study of WTC. The theoretical and empirical studies of WTC mentioned above are based on western context or second language background; indeed, there is a need to analyze WTC focusing on the eastern context or foreign language background in order to get a heuristic picture of WTC in language learning. The core question of this paper is to discuss the relationship between students' WTC and situational variable under Chinses classroom environment, offering a glimpse of WTC cultivation.

\section{MethodOLOGY}

\section{A. Research Questions}

The questions to be solved in this paper are listed as follows:

- How's the Chinese high school students' WTC in English inside the classroom?

- Does situational variable exert any influences on students' WTC in English inside the classroom?

\section{B. Selection of Subjects}

The subjects who participated in the present study were 134 high school students. The subjects took English course as a required course at least ten periods per a week at school. The selected classes were senior one and senior two, considering that students of senior three will participate in the college entrance examinations next year which may cause a negative influence on reliability of the survey data. Each grade contained two different classes ranging from advanced level to general level, according to their English exam scores divided by the school. Therefore, there were four classes numbered from 1 to 4 for data collection in this study. With an average age of 16,70 of them were male and 64 of them were female. The detailed information of the participants was detailed in the following "Table I": 
TABLE I.

THE DESCRIPTION OF THE SUBJECTS

\begin{tabular}{ccccc}
\hline & Number of subjects & Mean of age & Male & Female \\
\hline Class 1 & 31 & 15.4 & 16 & 15 \\
\hline Class 2 & 32 & 15.7 & 17 & 15 \\
\hline Class 3 & 34 & 16.2 & 18 & 16 \\
\hline Class 4 & 37 & 16.5 & 19 & 18 \\
\hline Sum & 134 & 15.9 & 70 & 64 \\
\hline
\end{tabular}

- Class 1 is advanced level of senior one, and class 2 is average level of senior one.

- Class 3 is advanced level of senior two, and class 4 is average level of senior two.

\section{Research Instrument}

The questionnaire was composed of two parts. Part 1 was about background information of the participants including name, age, sex, and years of studying English. Part 2 was willingness to communicate inside the classroom scale, adapted from MacIntyre, P. D., Baker, S. C., Clément, R., \& Conrod, S. (2001). The scale was covered by four basic language skills, namely speaking, listening comprehension, reading and writing. All items were measured on a 5-point Likert scale (i.e., $1=$ almost never willing, $2=$ sometimes willing, 3=willing half of the time, 4=usually willing, $5=$ almost always willing) to testify subjects' WTC in English inside the classroom. There were ten students selected as interviewees, according to their questionnaire scores, consisting top five high score students and top five low score students. Questions about the interview were around interlocutor, topic, and conversational context (Kang 2005). All the participants were given a choice to be interviewed in either Chinese or English, and only researcher-self was with the interviewee during the process.

\section{Data Collection and Data Analysis}

The researcher conducted the questionnaire and interview survey during self-study course without interrupting their ordinary study, after receiving the permission to carry out the investigation. Quantitative data collected from the questionnaire were analyzed with the aid of computer program SPSS. Qualitative data collected from the interview were coded by using content analysis.

\section{RESULTS AND DISCUSSIONS}

\section{A. The Quantitative Results}

According to the questionnaire data, analysis of WTC was generated to describe students' WTC in English inside the classroom. The results of four classes from different grade and level were presented in "Table II". As we can see from the table, the selected high school students had moderate WTC in English inside the classroom $(\mathrm{M}=3.289)$, between "sometimes willing" and "willing half of the time". The four classes' WTC were different, with a maximum of 3.439 and a minimum of 3.047. In sum, the WTC of senior one were higher than the WTC of senior two, meanwhile the $\mathrm{SD}$ of senior two were higher than the SD of senior one.

TABLE II. STUDENTS' WTC OF FOUR Classes

\begin{tabular}{ccc}
\hline & Mean & SD \\
\hline Class 1 & 3.439 & 0.746 \\
\hline Class 2 & 3.201 & 0.947 \\
\hline Class 3 & 3.234 & 0.972 \\
\hline Class 4 & 3.047 & 1.121 \\
\hline Sum & 3.289 & 1.206 \\
\hline
\end{tabular}

- Class 1 is advanced level of senior one, and class 2 is average level of senior one.

- Class 3 is advanced level of senior two, and class 4 is average level of senior two

\section{B. The Qualitative Results}

The semi-structural interview would focus on students' feelings towards the communicative activities happened in class. Based on the raw interview data, written scripts were transcribed. After several times of rereading and coding, some key categories were concluded as are shown in "Fig. 1". 
As for the aspect of interlocutor, three key words were noted - familiarity, number and attraction. For example, student A said "I would like to work with my friend to solve the classroom tasks". Student C said "When I am with my partner or my friend in class, I feel more comfortable to talk with them." Student D said "I don't want to work in pair with someone I don't know when I need to complete the task assigned by teacher". Thus, seven students had mentioned the familiarity with the interlocutor during the classroom interactive communication. Generally speaking, there are three classroom interactive patterns adopted by Chinese English teacher, including pair work, group work and wholeclass work. Hence, six students had shared their opinions about the number of participating interlocutors. For example, student B said "I will choose to express my viewpoint in pair work, rather than in front of the whole class". Student E said "I am usually more active with fewer listeners". Student F said "When I am in a pair work, I will share my opinion more freely. But when I am in a discussion group, I will think a lot before my talking". In the case of interlocutor's personal attraction, eight students had talked about it. Student C said "I will pay more attention to the interesting people whom I am talking with". Student G said "I would like to spend time with someone of great charm". Student H said "I enjoy working with attractive people to do classroom activities".

With regard to the aspect of topic, familiarity and interest were seen as the key categories. In fact, topic is the fundamental source of communication content which may determine the flow of interactive communication. Nine students had mentioned familiarity of the topic. For example, student B said "I am more confident and willing to talk about things that I have already known". Student J said "I usually don't want to express opinion on something of which I am not sure". Student H said "I am more talkative when it comes to the things I am familiar with". At the same time, interest was seen as a key code, because eight students had brought up this concept. For example, student D said "If the class activity is boring, I will not want to join in the discussion". Student F said "I would like to take part in the English tasks which can arouse my interest". Student I said "I think it is a terrible thing that you have to talk something boring". As to the aspect of conversational context, misunderstanding and problems were pointed out as key words. Six students had talked about misunderstanding during the interactive session. For example, student A said "Sometimes, when people cannot get my point or get it in a wrong way, I will feel upset and do not want to continue the communication". Student C said "It is really annoying that people cannot understand what you are talking about". Student G said that "I am worried when other classmates don't know my expressions during the class activity". Moreover, difficulties during the conversation were emphasized by eight interviewees. For example, student C said "When I engage in some class activities, I know it is inevitable there are problems to be solved, but sometimes, these problems are beyond my competence, and I feel confused to work out alone". Student E said "I like challenging tasks, and I am happy to see my progress after the brainstorm with other classmates". Student J said "Because of my limited competence, I will be afraid to tackle problems"

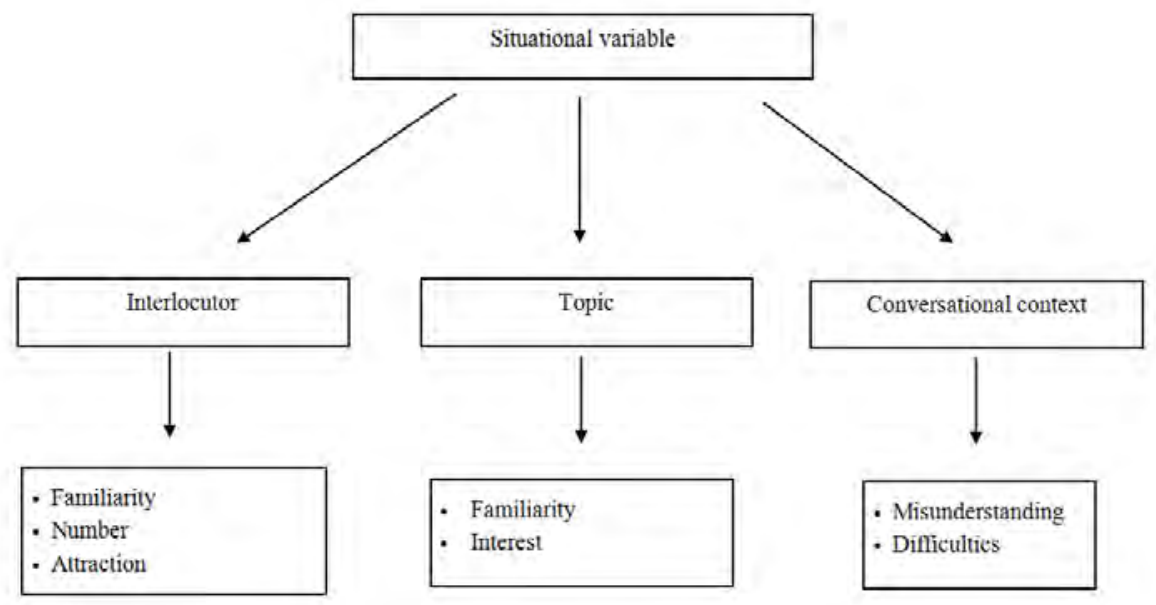

Fig. 1. Key labels of situational variable concluded from the interview.

\section{Discussion}

According to the quantitative analysis, this study shows that selected high school students had moderate WTC in English inside the classroom. The students do not have strong willingness or desire to communicate in English inside the classroom. Secondly, we find out that situational variable does influence students' WTC in English inside the classroom, when we look into the qualitative data of interview. Interlocutor, topic and conversational context are three core dimensions of situational variable, based on the descriptions of interviewees. Given the special nature of EFL and classroom instruction, the scope of interlocutor, topic and conversational context are pretty limited. The interlocutor mainly refers to classmates and teacher, while the topic and conversational context mainly confines to teaching materials and teaching style. However, some key points are repeatedly mentioned by interviewees, which deserve paying much more attention. The first thing teacher should have an eye on is to create an atmosphere which is 
free and secure for students to use English. On the one hand, familiar interlocutor and topic will enhance students' sense of security to communicate. The familiar interlocutor will let down students' guard to open his/her mind and mouth to engage in the class interaction. Also, the familiar topic will help students with more background knowledge to increase confidence during the communication. On the other hand, attractive interlocutor and topic will raise students' interests to communicate. Without no doubt, the interesting people and topic can boost students' desire to engage in the communication and play a role in the interaction. At last, teacher should be careful with students' error when students face with problems or difficulties in the conversation process. Because the improper measures towards students' mistakes can easily destroy students' confidence and willingness to communicate, leaving a psychological shadow.

\section{CONCLUSION}

The work of a good teacher not only is confined to the class, but extends to the preparation before the class and reflection after the class. The first important rule for teacher is to identify the gap between what students are able to do and what they need to be able to do. Briefly speaking, teacher should be aware of the differences between the existing condition of students and what is expected to students, known as need analysis. The term need has multilayered connotations, which is used to refer to wants, desires, demands, expectations, motivations, lacks, constrains, and requirements (Brindley, 1984). Need analysis is a distinct and necessary phase for teacher in instruction design and lesson plan. After fully considering the present abilities and needs of students, teacher can prepare the instructional plan and select classroom activities under the guidance of specific teaching goals. Therefore, teacher should take students' communicative need seriously, since "the need for interaction and the desire to communicate are universal" (Wen \& Clément, 2003: 25). In other words, teacher should select and reevaluate the teaching content after setting WTC as an important goal and giving the priority to students' communicative needs.

The second rule for teacher is to set varied tasks and activities in class, because students' WTC are represented and enhanced through different kinds of tasks and activities in English class. Different type of tasks and activities can be carried out in class according to different teaching material and goals, such as information-gap activities, interpretationgap activities, opinion-gap activities, skill-getting activities, skill-using activities, and pedagogical activities. Making good use of these various tasks can help teacher broaden the content and form of language learning, and integrate the classroom organization in an organic way. Moreover, the theme and the form of classroom activities should manifest the character of variety, creativity and flexibility. It is teacher's task to select and determine the right theme and form of classroom activities, in order to fit in the studentcentered belief and communication oriented objective. Also, these activities should be attractive and creative enough to catch students' attention and interest. Besides the various types of interactive activities in class, teacher should also delicately select the content for activities. On the one hand, the content of interactive tasks must not rely on fabricated materials which are marked with drills and repetition, but use real life situations as a basis that necessitate communication. Teacher can rehearse communicative practices which would really happen in real world. On the other hand, the content of interactive activities should be close to students' life, because the prior knowledge or background information can provide students with more common sense and help students overcome the communicative obstacles in the process of interactive activities.

\section{REFERENCES}

[1] McCroskey, J. C., \& Richmond, V. P. (1987). Willingness to communicate. In J. C. McCroskey, \& J. A. Daly (Eds.), Personality and interpersonal communication (pp.129-156). Newbury Park, CA: Sage.

[2] MacIntyre, P. D., Clément, R., Dornyei, Z. \& Noels, K. A. (1998). Conceptualizing willingness to communicate in a L2: A situational model ofL 2 confidence and affiliation. The Modern Language Journal, $82,545-562$.

[3] Muriel Saville-Troike. (2006). Introducing Second Language Acquisition. UK: Cambridge University Press.

[4] MacIntyre, P. D., Baker, S. C., Clément, R., \& Conrod, S. (2001). Willingness to communicate, social support and language-learning orientations of immersion students. Studies in Second Language Acquisition, 23, 3, 369-388

[5] Kang, Su-Ja. (2005). Dynamic emergence of situational willingness to communicate in a second language. System, 33, 277-292.

[6] Brindley, G. (1984). The role of needs analysis in adult ESL programme design. In R.K.Johnson (Eds), The second language curriculum. New York: Cambridge University Press.

[7] Wen, W. P. \& R. Clement. (2003). A Chinese conceptualization of willingness to communicate in ESL. Language, Culture and Curriculum, 16, 18-38. 